\title{
Effect of Grid Faults on Dominant Wind Generators for Electric Power System Integration: A Comparison and Assessment
}

\author{
Mohamed Metwally Mahmoud ${ }^{1 *}$, Mohamed Khalid Ratib ${ }^{1}$, Mohamed M. Aly², Abdel-Moamen M. Abdel-Rahim ${ }^{1}$
}

${ }^{1}$ Department of Electrical Engineering, Faculty of Energy Engineering, Aswan University, 81528 Aswan, Egypt
${ }^{2}$ Department of Electrical Engineering, Faculty of Engineering, Aswan University, 81542 Aswan, Egypt.

\begin{abstract}
In recent times, various types of wind generators have been linked to the power grids globally and the focus has been to control them to be more efficient and reliable. This study concisely discusses performance analysis, modeling, and assessment of different wind generators (permanent magnet synchronous generator, doubly-fed induction generator, squirrel cage induction generator), covering their benefits, drawbacks, and impact on the electric power systems. This comparison aims to guarantee that their technical and economic evaluations are comparable, allowing engineers to make a more informed decision about which generator is best suitable for their installation. Findings for the investigated wind generators lead to significant observations about their application fields, such as permanent magnet synchronous generator outperforms doubly-fed induction generator and squirrel cage induction generator, especially during grid disruptions; on the other hand, squirrel cage induction generator is simple and inexpensive.
\end{abstract}

Index Terms: doubly-fed induction generator (DFIG), modeling, power system disturbance, permanent magnet synchronous generator (PMSG), squirrel cage induction generator (SCIG), wind generators.

\section{ABBREVIATIONS}

WG - wind generator

PMSG - permanent magnet synchronous generator

DFIG - doubly-fed induction generator

SCIG - squirrel cage induction generator

RES - renewable energy sources

\footnotetext{
${ }^{*}$ Corresponding author.

E-mail: metwally_m@aswu.edu.eg
}

http://dx.doi.org/10.38028/esr.2021.03.0007

Received September 26, 2021. Revised October 11, 2021.

Accepted October 23, 2021. Available online November 28, 2021.

This is an open access article under a Creative Commons Attribution-NonCommercial 4.0 International License.

(C) 2021 ESI SB RAS and authors. All rights reserved.
WT - wind turbine

NN - neural network

EST- energy storage tools

FACTS - flexible alternating current transmission system

FLC - fuzzy logic controller

WECS - wind energy conversion system

VSWG - variable-speed wind generator

FSWT - fixed-speed wind turbine

GSC - grid-side converter

VSC - voltage-source converter

IGBT - insulated-gate bipolar transistor

MSC - machine-side converter

MPPT - maximum power point tracking

\section{INTRODUCTION}

Renewable energy use has risen dramatically in current years all around the universe. The large-scale integration of renewable energy sources (RESs) into electrical grids has resulted in significant changes in power production technologies. This progress has been made possible by more effective management and enhancement of the electrical components, both of which have contributed to the improvement of the quality of the power delivered [1]. RESs offer a great potential to help certain regions grow sustainably while also giving a lot of socioeconomic advantages. Diversity of electricity supply, environmental sustainability, and the establishment of new industry and business possibilities are among the RES advantages [2, 3].

Due to the international agreements achieved, we might be witnessing the rupture of the link between electricity generation and $\mathrm{CO} 2$ emissions nowadays [4]. As seen in Fig. 1, more than a 50\% increase in the global electricity demand is expected by 2030 , while the amount of $\mathrm{CO} 2$ released by this sector remains stable. This can be a turning point since increments in electricity consumption have always been coupled with proportional rises in $\mathrm{CO} 2$ emissions. This switching is a consequence of the expected and necessary transformation in the electrical energy sector. Around $70 \%$ of the new electricity generation units are projected to be low-carbon technologies raising the total share of these sources to nearly $45 \%$ of overall generation by 2030 [4]. Inevitably, RESs have a central 


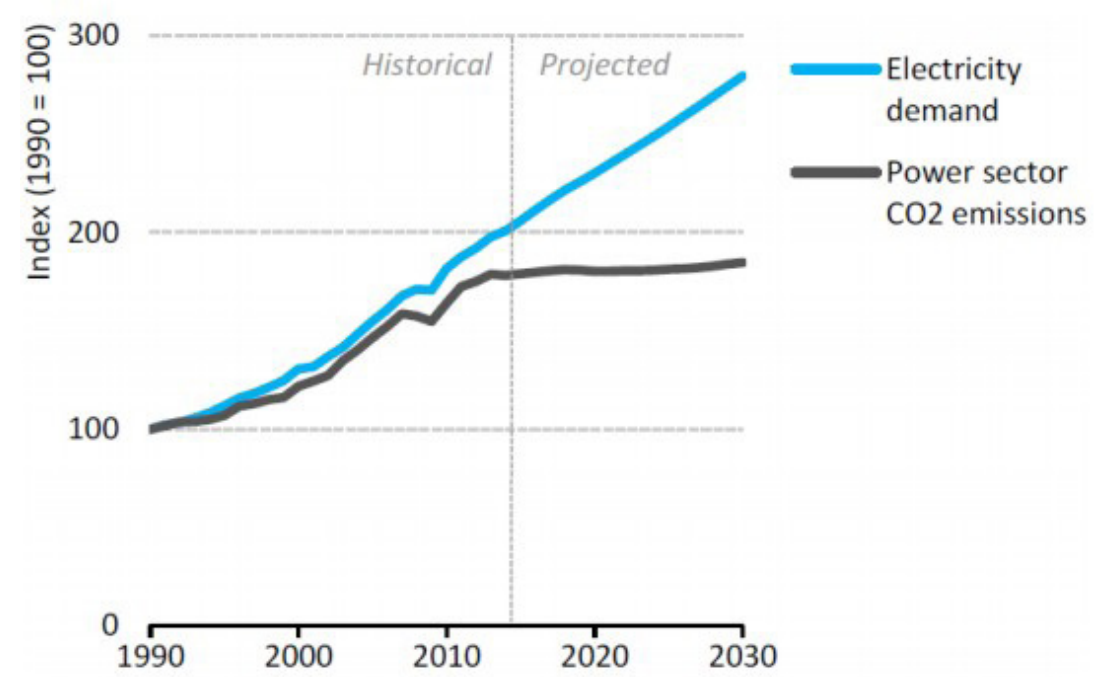

Fig. 1. Growth in world electricity demand and related CO2 emissions since 1990 [4].

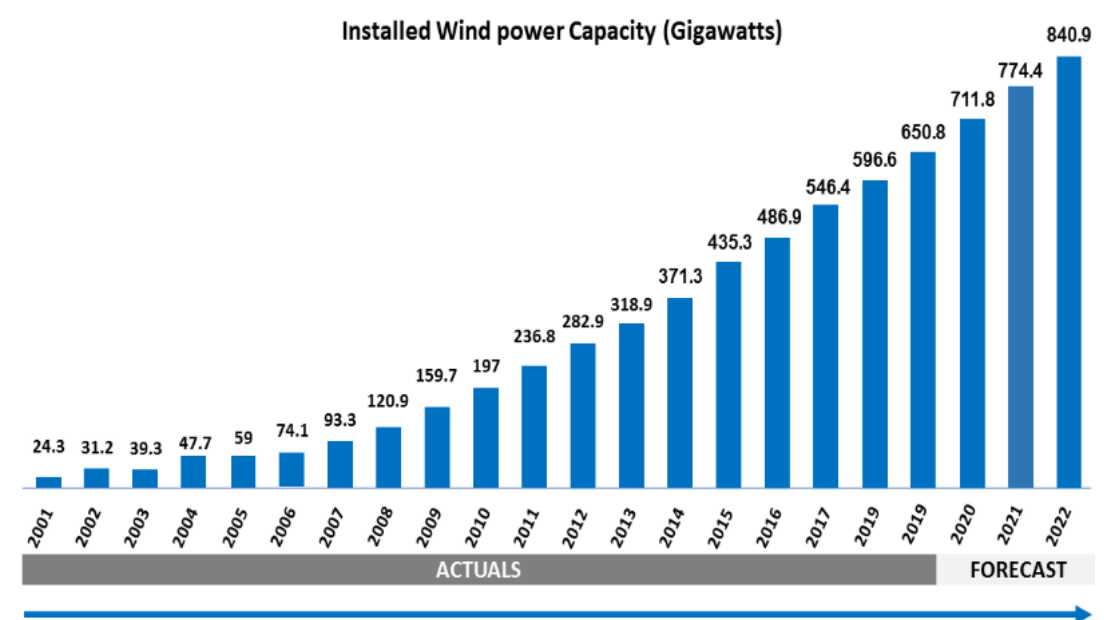

Fig. 2. Global installed wind power capacity.

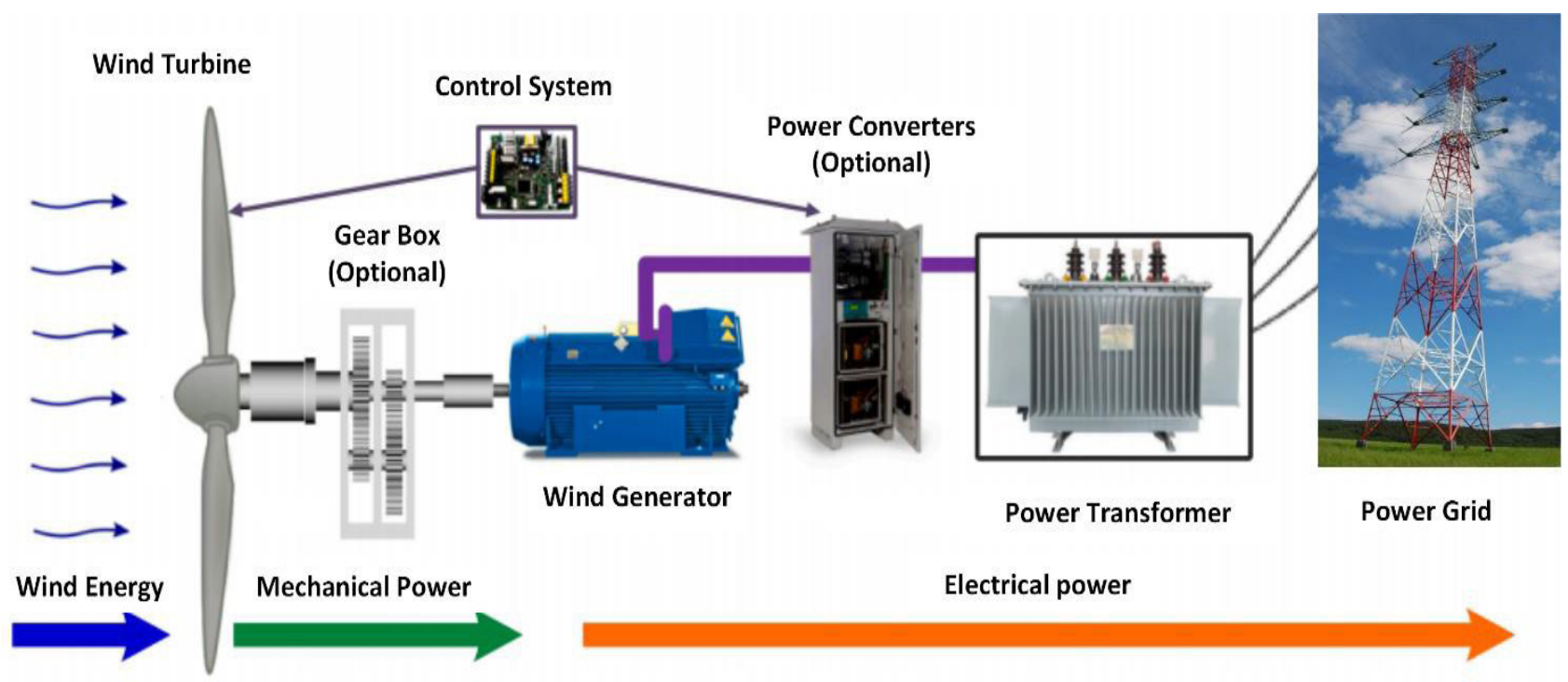

Fig. 3. General working principle of the WECS operation 


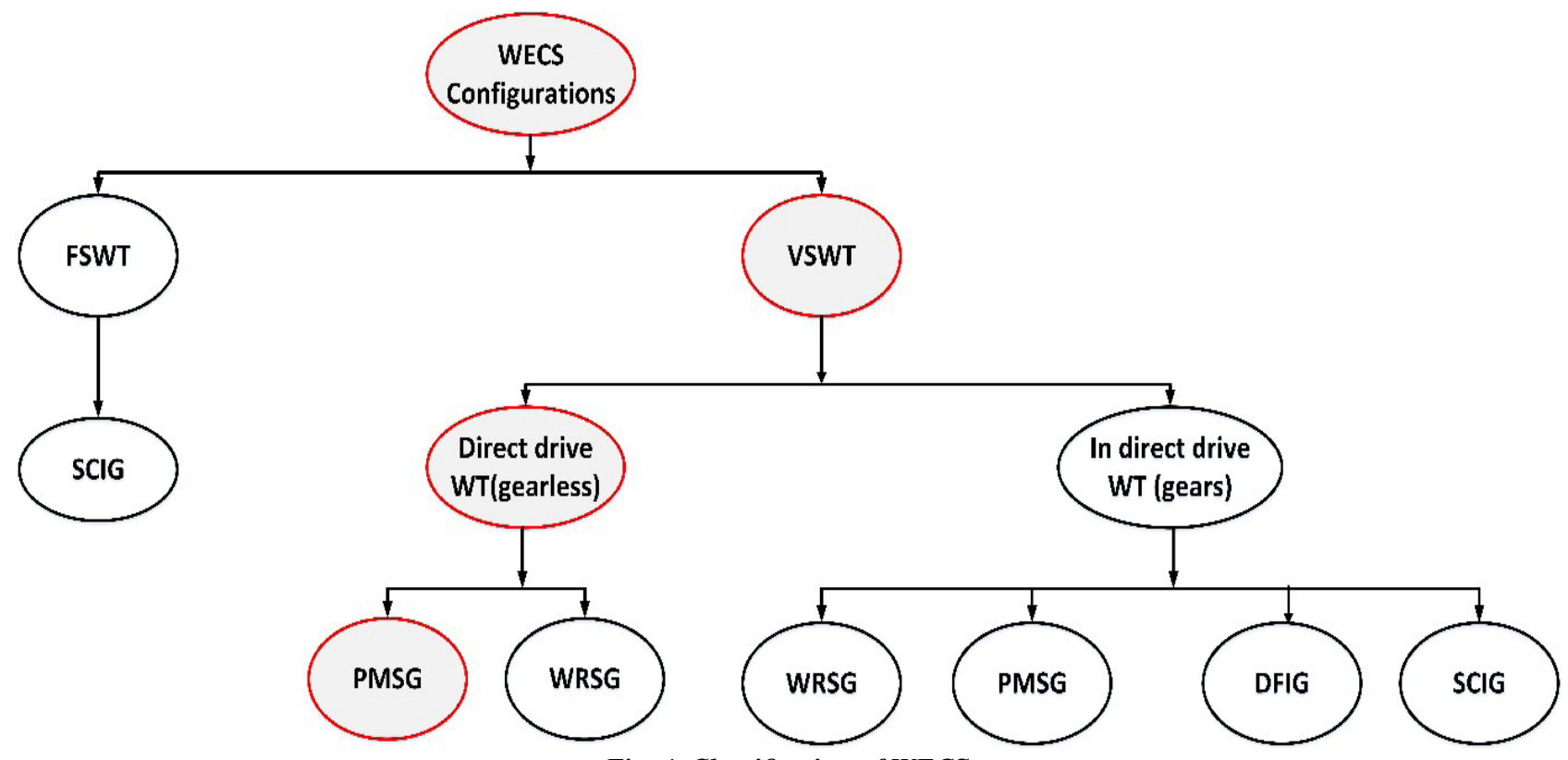

Fig. 4. Classification of WECS.

role to play here. For instance, estimations of $4000 \%$ and $1000 \%$ growth in the total final energy consumption share of solar PV and wind generators (WGs), respectively, were reported in the literature [5]. Compared with other RESs, wind energy is inexpensive, produces energy with negligible environmental impacts, and is more dependable. The wind power capacity installed globally from 2001 to 2022 is shown in Fig. 2 [6].

The study of wind speed and other wind characteristics in a given location is critical for building wind turbines (WTs) on land or in the water. The Weibull is particularly useful for analyzing the data of wind velocity probability density in WT systems. In addition, data from the fluctuation of average wind speed can be obtained by applying Prandtl's law. Nevertheless, different technologies and existing WT designs should be considered to select the one that performs well in a specific application. Wind energy is a plentiful resource given by mother nature [7, 8]. Furthermore, the worldwide availability of this sort of RES makes it suitable for autonomous energy production. Old WGs operate at a fixed speed, while modern WGs can operate at variable speeds and meet the new grid requirements [6].

Various software and hardware solutions have been used for improved and efficient operation of the grid-connected WGs. The software schemes include PI-optimization methods, FLC and its modifications, and neural networks (NNs) [9, 10]. Complex nonlinear troubles can be solved using some heuristic methods with minimal computational time but with poor accuracy solutions [11, 12]. Hardware approaches are based on energy storage tools (ESTs), FACTS tools, or a hybrid of both to improve the grid integration capabilities [13].

The purpose of the study provided in this paper is to compare and evaluate the most popular WGs currently existing in the market. In addition, the influence of grid faults on various WGs has been studied, and their benefits and drawbacks are provided to aid researchers to more deeply understand their actions during grid fail. The assessment of WGs carried out in this study is to assist the researchers in selecting the most appropriate WG for their specific use.

This paper can be outlined as follows. Section 2 presents the characteristics of SCIG, DFIG, and PMSG with the operating concept of WECSs. Section 3 focuses on the mathematical model of the WT system and the aforementioned WGs. The advantages and disadvantages of WGs under investigation are discussed in Section 4, while the local grid implications on the three major WGs are summarized in Section 5. Section 6 assesses the studied WGs. The major concluding remarks are presented in Section 7.

\section{CONFIGURATIONS OF DOMINANT WIND GENERATORS}

Advanced technologies are being applied to WECSs to make them more effective and achieve the grid necessities. This study concerns the three most common WGs, which are SCIG, DFIG, and PMSG.

\section{1) Working principle of WECS}

The working principle of the WECS involves two stages. In the first stage, the kinetic energy in the wind is being captured and converted into mechanical energy through the blades of the aerodynamic WT rotor. The second stage is electromechanical power conversion, which employs an electrical generator that converts mechanical energy into electrical energy to be transmitted to an electrical power grid [14]. This is the general principle of operation, and it is shown schematically in Fig. 3.

2) Classification of WECS 


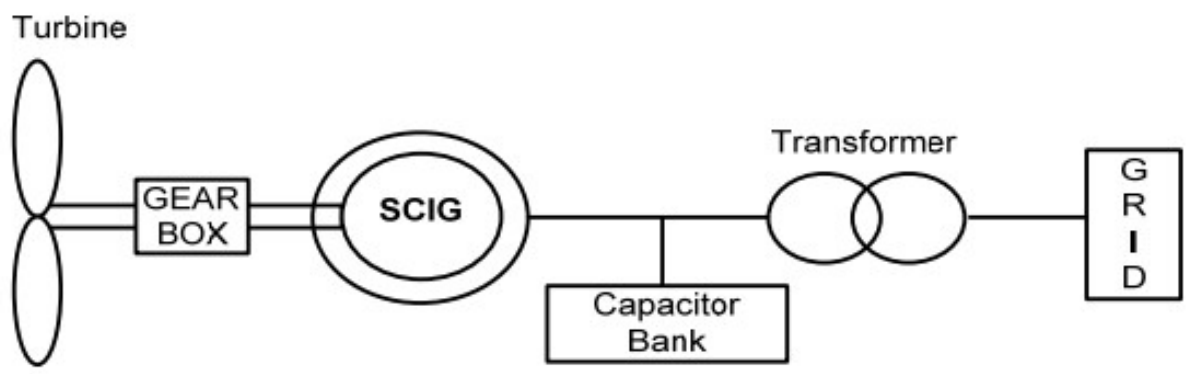

(a)

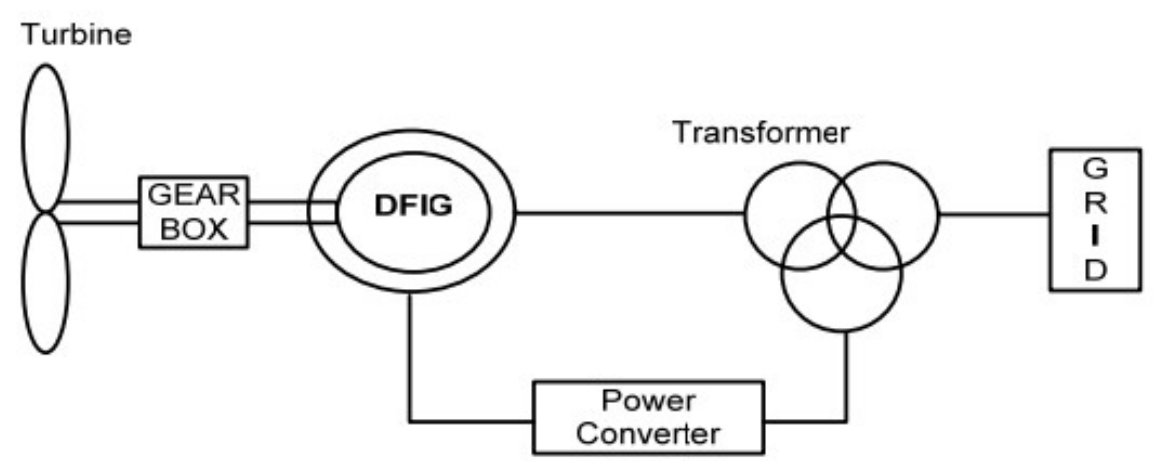

(b)

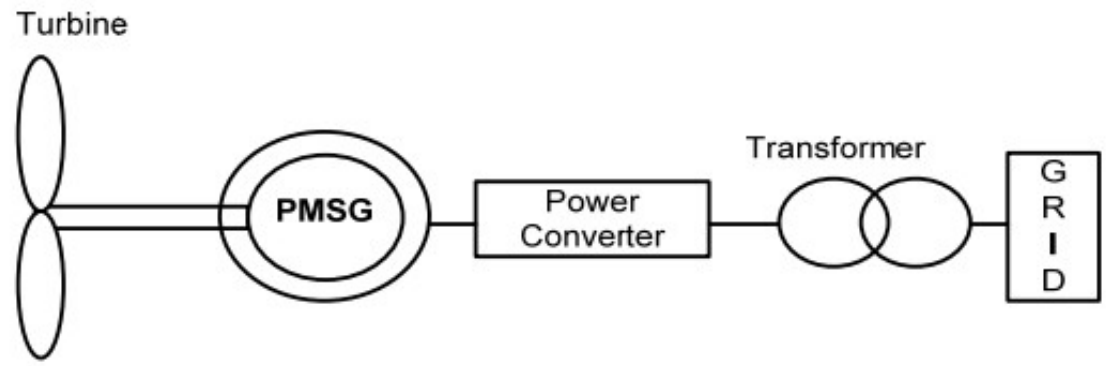

(c)

Fig. 5. Generating systems used in WECSs: (a) SCIG, (b) DFIG, and (c) PMSG.

Based on their operational speed, WECSs can be classified into two main categories: fixed speed WTs and variable speed WTs. Moreover, they can also be subdivided into many different types based on their ability, reliability, efficiency, performance, and minimal cost [14]. Fig. 4 shows the classifications of WECSs. As regards the construction of their generating system, almost all of the currently mounted WTs use one of the configurations shown in Fig. 5.

\section{a) SCIG technology}

SCIG is the first electrical generator used to generate electrical power by capturing the power of the wind. The output of SCIG is used to be directly connected to the power grid through a power transformer, which results in its rotor speed varying slightly according to the amount of power needed by the grid. However, these variations are as small as 1 to $2 \%$ of its rated speed. Accordingly, it is often called a constant speed or FSWT. Impressively by altering the number of pole pairs of its stator winding, the SCIGs, equipped with WTs, can run at two completely different (but constant) speeds. SCIG needs a continuous supply of reactive power for its operation, which is undesirable, especially when it connects large WTs to weakened grids. Thus, capacitors play a significant part for SCIG by supplying fully or partially the amount of reactive power needed for the generator to achieve unity or near-unity power factor. There are considerable hazards related to this generator, i.e., the power captured from the wind is 


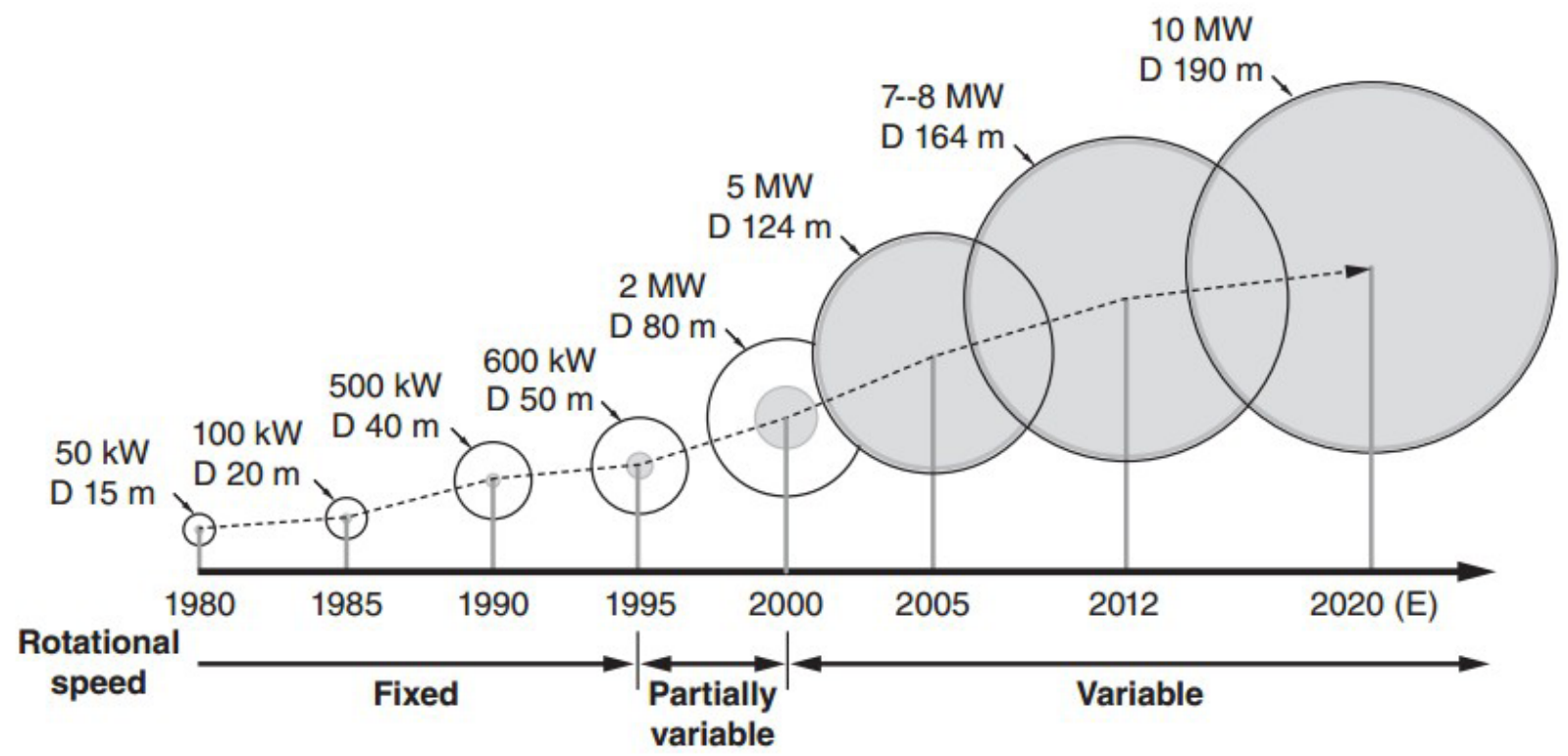

Fig. 6. State-of-the-art development-wind generators.

sub-optimal, it is exposed to danger due to self-excitation for the period of the power grid interruption, and reactive power compensation is required [15].

\section{b) DFIG technology}

DFIG is viewed as a starting point for the VSWG because its mechanical rotor speed can be easily decoupled from the power frequency of the electrical power grid. This can be achieved by using a power electronic converter to feed 3-phase power to the DFIG rotor windings, as shown in Fig.5. In this way, the mechanical and electrical frequencies of the rotor can be decoupled, and consequently, the electrical frequency of the rotor could be aligned to its stator counterpart and independently of the rotor's mechanical speed. Change in the DFIG's rotor resistance can result in a shift of the torque/speed characteristics of the generator and an increase in transient rotor speed of about $10 \%$ of the nominal rotor speed [15].

\section{c) PMSG technology}

PMSG is the first generator to make a complete benefit of the power electronic converters to be decoupled from the power grid. The used GSC is a VSC, i.e., IGBT bridge. The MSC can be either a VSC for a large scale, in MW, or a diode rectifier for a small scale, in $\mathrm{kW}$. It is characterized by self-excitation, simple structure, high power density, low maintenance, absence of gears, good controllability, and full-scale power electronics interface. It is one of the most attractive and promising WGs due to its reported merits $[12,16]$.

SCIG, DFIG, and PMSG represent about 97\% of generators in the market these days. It is clear from Fig. 6 that before 1995, WGs had been based on FSWTs due to their simplicity and low cost, but their main drawback is the need for reactive power to assist voltage support. In 1995-2000, DFIG became the dominant sector due to its merits like reduced cost and the presence of power electronic converter. Due to the problems with the earlier two WGs, PMSG is currently the major WG that can meet MPPT and new grid code requirements. The main cause of the rapid growth of VSWTs is the advance in power converters technology $[17,18]$.

\section{MODELING OF DOMINANT WIND GENERATORS}

1) WT model

The WT model can be articulated as follows [12, 13]:

$$
\begin{gathered}
C p(\lambda, \beta)=0.5176\left(\frac{116}{\lambda_{i}}-0.4 \beta-5\right) \exp ^{-\frac{21}{\lambda_{i}}}+0.0068 \lambda, \\
\lambda=\frac{\omega_{r} R}{V_{W}}, \\
T_{m}=\frac{P_{m}}{\grave{\mathrm{u}}_{r}}, \\
T_{m}=J_{e q} \frac{d \omega_{r}}{d t}+B_{e q} \omega_{r}+T_{e},
\end{gathered}
$$

where, $C p, \lambda, \omega_{r}, J_{e q}, B_{e q}, T_{e}, T_{m}$ are the studied WT parameters defined in [12].

2) PMSG model

The PMSG's concept is fully defined in [12] and can be represented as follows:

$$
\begin{aligned}
& V_{d s}=R_{s} I_{d}+\lambda_{d}-\omega_{e} \Psi_{q}, \\
& V_{q s}=R_{s} I_{q}+\lambda_{q}-\omega_{e} \Psi_{d} .
\end{aligned}
$$

The stator flux connection components can be written as:

$$
\begin{gathered}
\psi_{d}=L_{d} I_{d}+\psi_{p m}, \\
\psi_{q}=L_{q} I_{q}, \\
\lambda_{d}=L_{d} I_{d}+\psi_{p m} .
\end{gathered}
$$

The $T_{e}$ can really be defined in the following way: 


$$
T_{e}=\frac{3}{2} n_{p}\left(\lambda_{d} I_{q}-\psi_{q} I_{d}\right)=\frac{3}{2} n_{p}\left(\psi_{p m} I_{q}+I_{d} I_{q}\left(L_{d}-L_{q}\right)\right) .
$$

For the surface-mounted PMs sort, $\left(L_{q}=L_{d}\right)$. So, $T_{e}$ can be written as tracks:

$$
T_{e}=\frac{3}{2} n_{p}\left(\psi_{p m} I_{q}\right) .
$$

\section{3) DFIG model}

The DFIG concept is discussed and defined in [19] and can be exemplified as follows:

$$
\begin{gathered}
V_{d s}=R_{s} I_{d s}-\frac{d \psi_{d s}}{d t}-\omega_{s} \psi_{q s}, \\
V_{q s}=R_{s} I_{q s}+\frac{d \psi_{q s}}{d t}+\omega_{s} \psi_{d s}, \\
V_{d r}=R_{r} I_{d r}+\frac{d \psi_{d r}}{d t}-\left(\omega_{s}-\omega_{r}\right) \psi_{q r}, \\
V_{q r}=R_{r} I_{q r}+\frac{d \psi_{q r}}{d t}+\left(\omega_{s}-\omega_{r}\right) \psi_{d r}, \\
\psi_{d s}=L_{s} I_{d s}+L_{m} I_{d r}, \\
\psi_{q s}=L_{s} I_{q s}+L_{m} I_{q s}, \\
\Psi_{d r}=L_{r} I_{d r}+L_{m} I_{d r}, \\
\psi_{q r}=L_{r} I_{q r}+L_{m} I_{q s}, \\
T_{e}=\frac{3}{2} P\left(\Psi_{d s} I_{q s}-\Psi_{q s} I_{d s}\right) .
\end{gathered}
$$

\section{4) SCIG model}

The dynamic behavior of the SCIG-WG is given as follows [20]:

$$
\begin{gathered}
V_{q s}=R_{s} I_{q s}+P \lambda_{q s}+\omega \lambda_{d s}, \\
V_{d s}=R_{s} I_{d s}+P \lambda_{d s}-\omega \lambda_{q s}, \\
V_{q r}=R_{r} I_{q r}+P \lambda_{q r}+\left(\omega-\omega_{r}\right) \lambda_{d r}=0, \\
V_{d r}=R_{r} I_{d r}+P \lambda_{d r}-\left(\omega-\omega_{r}\right) \lambda_{q r}=0,
\end{gathered}
$$

$$
\begin{gathered}
{\left[\begin{array}{c}
I_{d s} \\
I_{q s} \\
I_{d r} \\
I_{q r}
\end{array}\right]=\frac{1}{D_{1}}\left[\begin{array}{cccc}
L_{r} & 0 & -L_{m} & 0 \\
0 & L_{r} & 0 & -L_{m} \\
-L_{m} & 0 & L_{s} & 0 \\
0 & -L_{m} & 0 & L_{s}
\end{array}\right]\left[\begin{array}{c}
\lambda_{d s} \\
\lambda_{q s} \\
\lambda_{d r} \\
\lambda_{q r}
\end{array}\right],} \\
\lambda_{d s}=\left(V_{d s}-R_{s} I_{d s}+\omega \lambda_{q s}\right) / S, \\
\lambda_{q s}=\left(V_{q s}-R_{s} I_{q s}-\omega \lambda_{d s}\right) / S, \\
\lambda_{d r}=\left(V_{d r}-R_{r} I_{d r}+\left(\omega-\omega_{r}\right) \lambda_{q r}\right) / S, \\
\lambda_{q r}=\left(V_{q r}-R_{r} I_{q r}-\left(\omega-\omega_{r}\right) \lambda_{d r}\right) / S, \\
\left.D_{1}=L_{s} L_{r}-\left(L_{m}\right)^{2}, \lambda_{q s}\right) . \\
T_{e}=1.5 P\left(I_{q s} \lambda_{d s}-I_{d s} \lambda_{q s}\right) .
\end{gathered}
$$

\section{BENEFITS AND DRAWBACKS OF THE COMPARED WIND GENERATORS}

\begin{tabular}{|c|c|c|c|}
\hline Generator & SCIG & DFIG & PMSG \\
\hline \multirow{6}{*}{ 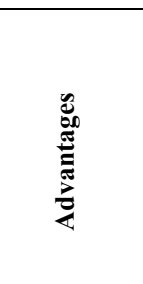 } & Simple and robust & Less mechanical stress & Negligible mechanical stress \\
\hline & Less expensive & Small converter & Absence of gearbox \\
\hline & Electrically efficient & Aerodynamically Efficient & Aerodynamically Efficient \\
\hline & Standard WG & Standard WG & Standard WG \\
\hline & - & MPPT operation & MPPT operation \\
\hline & - & Variable speed & Variable speed $(0-100 \%)$ \\
\hline \multirow{6}{*}{ 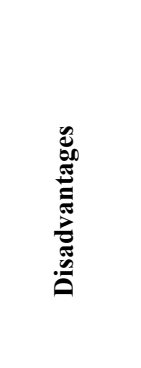 } & $\begin{array}{l}\text { Achieves grid codes using } \\
\text { costly hardware solutions only }\end{array}$ & $\begin{array}{l}\text { Achieves grid codes using hardware solutions } \\
\text { only }\end{array}$ & $\begin{array}{l}\text { Achieves grid codes using either hardware } \\
\text { or software solutions }\end{array}$ \\
\hline & Aerodynamically less efficient & $\begin{array}{l}\text { Electrically less efficient and affected by the grid } \\
\text { disturbances }\end{array}$ & Heavy and large \\
\hline & Gearbox is essential & Gearbox is essential & Power converter is a must \\
\hline & Mechanical stresses & High cost & - \\
\hline & Noise and vibration & Complex control & \\
\hline & $\begin{array}{l}\text { Necessity of large and } \\
\text { expensive compensation units }\end{array}$ & Speed varies about $30 \%$ of rated speed only & \\
\hline
\end{tabular}

Table 1 shows a comparative analysis of the three types of generators discussed in this study. The benefits and drawbacks of these generating systems are compared against each other and listed concisely in the Table.

\section{LOCAL GRID IMPACTS ON THE COMMON WIND GENERATORS}

High wind power penetration has resulted in some noticeable local impacts on the power system, including changes in node voltage, fault currents, harmonics, and flicker [21, 22]. A comparison of these impacts and their effects on the three WGs are stated briefly in Table 2.

\section{ASSESSMENT OF WIND GENERATORS}

Both technological and economic considerations should be addressed while selecting the kind of WG for specific conditions and applications. According to previous research, the SCIG voltage decreases most after a threephase failure, requiring more time to recover while also using reactive power. Stator voltage and rotor speed instability may occur as a result of this. On the other hand, when a PMSG is subjected to a 3-phase fault, the

Table 1. Benefits and drawbacks of the more used generating systems. 
Table 2. Effects of grid's local impacts on the three dominant wind generators.

\begin{tabular}{|c|c|c|c|}
\hline Local impact & SCIG & DFIG & PMSG \\
\hline $\begin{array}{l}\text { Changes in grid } \\
\text { voltage }\end{array}$ & $\begin{array}{l}\text { Compensation is a must, } \\
\text { using FACTS tools or storage } \\
\text { systems }\end{array}$ & $\begin{array}{l}\text { Compensation is } \\
\text { feasible, however, it is } \\
\text { contingent on the } \\
\text { converter's rating }\end{array}$ & $\begin{array}{l}\text { Compensation is possible, however, it is conditional on the } \\
\text { converter's rating }\end{array}$ \\
\hline Harmonics & $\begin{array}{l}\text { Hot point of research and } \\
\text { interest, and a major issue }\end{array}$ & $\begin{array}{l}\text { Less interest, and is not } \\
\text { a major issue }\end{array}$ & Least interest, and is not a major issue \\
\hline Flicker & $\begin{array}{l}\text { Important, due to absence of } \\
\text { power converters }\end{array}$ & $\begin{array}{l}\text { Important, due to partial } \\
\text { scaling of power } \\
\text { converters }\end{array}$ & $\begin{array}{l}\text { Unimportant, due to high system inertia and full scaling of } \\
\text { power converters }\end{array}$ \\
\hline Fault current sharing & $\begin{array}{l}\text { Large share, due to direct } \\
\text { connection to power grid }\end{array}$ & $\begin{array}{l}\text { Small share, due to } \\
\text { partial existence of } \\
\text { power converters }\end{array}$ & $\begin{array}{l}\text { No share, due to power converter's fault current blocking } \\
\text { capability }\end{array}$ \\
\hline
\end{tabular}

grid voltage is higher than that with DFIG used. The employment of power converter units allows the regulation of reactive power during breakdowns, which helps to reduce voltage fluctuations.

Previously, if severe difficulties arose, WGs linked to the grid were typically just unplugged. Nowadays, many nations have mandated that WGs should not only stay attached but also help in the event of a severe grid outage. PMSG and DFIG are superior to SCIG in terms of meeting this criterion. PMSG can supply more reactive power to the grid during or after a failure than DFIG, and PMSG meets the additional standards better than DFIG.

Existing WGs are meant to operate for 120000 hours through the course of their 20-year life span. The expenditures of operation and maintenance can make up $10-20 \%$ of the overall cost of a WG system. The cost of operations is determined by the number of jobs given and the size of the wind project, not by the kind of WG [23].

Since direct drive (PMSG) systems do not include a gearbox, their maintenance costs are different from those of other systems. The repair cost is higher for WGs that employ gearboxes because they have more rotating components (gearboxes) and wearing points necessitating more repair. As a result, the cost of maintaining WGs incorporating gearboxes is often $1 \%$ greater than that of PMSG systems.

As the size of WGs has grown, it becomes challenging to develop dependable gearboxes that can resist the massive pressures they must endure. As per a current survey, some WGs in a five-year-old wind farm are now on their second or third gearbox retrofit. In regions with high wind instability, such as mountainous terrain, a gearbox is more prone to wearout. For example, if a $1.5 \mathrm{MW}$ WG gearbox is rebuilt at a local repair shop in the United States, it will cost between $\$ 150000$ and $\$ 200000$, accounting for $10 \%$ to $15 \%$ of the entire project capital cost. However, with the gearbox to be delivered and repaired outside of the United States, an additional $80 \%$ of the cost must be paid [24].

PMSG systems do not have a gearbox, therefore, this problem never arises. In this example, the overall project cost of employing these technologies is less than that of using a gearbox system. Nevertheless, if the PMSG-WG systems fail, their repair costs will also be appreciable because their primary shaft, bearings, and rotor are usually incorporated into one framework, and their scale is large.

\section{CONCLUSIONS}

Wind energy is becoming more widely used globally, and several technological advances are being used to design new WGs. The three major WGs have been modeled, with grid implications studied and assessed herein in this paper. In addition, their benefits and drawbacks have been discussed. Since SCIG-WGs lack reactive power management, they are utilized only by tiny wind farms. Although DFIGs require smaller initial capital and have been deployed more widely than PMSGs, PMSGs can maintain grid voltage better than DFIGs during failures. When maintenance is factored in, all turbine models have equal long-term costs.

\section{REFERENCES}

[1] REN21, Renewables 2020 Global Status Report. 2020.

[2] M. K. Ratib and A. Rashwan, "Amplitude Sampled Reference-Based Space Vector Pulse Width Modulation for Control of Voltage Source Converters," Energy Syst. Res., vol. 4, no. 2, pp. 46-63, 2021, DOI: 10.38028/esr.2021.02.0005. 
[3] N. Sekhar and N. Kumaresan, "Operation and control of a stand-alone power system with integrated multiple renewable energy sources," Wind Eng., 2021, DOI: $10.1177 / 0309524 X 211024126$.

[4] M. van der Hoeven, "Energy and Climate Change: World Energy Outlook Special Report", International. Energy Agency (IEA), France, Paris, 2015.

[5] D. Saygin, R. Kempener, N. Wagner, M. Ayuso, and D. Gielen, "The Implications for Renewable Energy Innovation of Doubling the Share of Renewables in the Global Energy Mix between 2010 and 2030," Energies, vol. 8, no. 6, pp. 5828-5865, 2015, DOI: 10.3390/en8065828.

[6] M. M. Mahmoud, M. Khalid Ratib, M. M. Aly, and A. M. M. Abdel-Rahim, "Wind-driven permanent magnet synchronous generators connected to a power grid: Existing perspective and future aspects," Wind Eng., 2021, DOI: 10.1177/0309524X211022728.

[7] M. M. Mahmoud, M. M. Aly, H. S. Salama, and A. M. M. Abdel-Rahim, "Dynamic evaluation of optimization techniques-based proportional-integral controller for wind-driven permanent magnet synchronous generator," Wind Eng., vol. 45, no. 3, pp. 696-709, 2021, DOI: 10.1177/0309524X20930421.

[8] M. M. Mahmoud, H. S. Salama, M. M. Aly, and A. M. M. Abdel-Rahim, "Design and implementation of FLC system for fault ride-through capability enhancement in PMSG-wind systems," Wind Eng., vol.45, no. 5, pp. 1361-1373, 2020, DOI: 10.1177/0309524X20981773.

[9] M. M. Mahmoud, A. Mohamed Hemeida, and A. M. M. Abdel-Rahim, "Behavior of PMSG Wind Turbines with Active Crowbar Protection under Faults," in 2019 Innovations in Power and Advanced Computing Technologies, i-PACT 2019, 2019, pp. 1-6, DOI: 10.1109/i-PACT44901.2019.8960004.

[10] P. Wang, P. Wang, and E. Fan, "Neural network optimization method and its application in information processing," Math. Probl. Eng., vol. 2021, 2021, DOI: $10.1155 / 2021 / 6665703$.

[11] C. Kongnam and S. Nuchprayoon, "A particle swarm optimization for wind energy control problem," Renew. Energy, vol. 35, no. 11, pp. 2431-2438, 2010, DOI: $10.1016 /$ j.renene.2010.02.020.

[12] M. M. Mahmoud, M. M. Aly, and A.-M. M. AbdelRahim, "Enhancing the dynamic performance of a wind-driven PMSG implementing different optimization techniques," SN Appl. Sci., vol. 2, no. 4, p. 684,2020 , DOI: 10.1007/s42452-020-2439-3.

[13] M. M. Mahmoud, A. M. Hemeida, T. Senjy, and A. M. Ewais, "Fault Ride-Through Capability Enhancement for Grid- Connected Permanent Magnet Synchronous Generator Driven by Wind Turbines," in IEEE Conference on Power Electronics and Renewable Energy, CPERE 2019, 2019, pp. 567-572, DOI: 10.1109/CPERE45374.2019.8980139.

[14] S. Sumath, L. Ashok Kumar, and P. Surekha, "Wind energy conversion systems," in Green Energy and Technol., vol. 214, Springer, Cham, 2015, pp. 247-
307, DOI: 10.1007/978-3-319-14941-7_4.

[15] H. Li and Z. Chen, "Overview of different wind generator systems and their comparisons," IET Renew. Power Gener., vol. 2, no. 2, pp. 123-138, 2008, DOI: 10.1049/iet-rpg:20070044.

[16] N. A. Elsonbaty, M. A. Enany, and M. Elymany, "Concurrent unity power factor and constant mutual flux control for PMSG-WT MPPT,” Wind Eng., 2020, DOI: 10.1177/0309524X20968872.

[17] J. Kauffman and K. M. Lee, Handbook of Sustainable Engineering. Dordrecht, NewYork: Springer, 2013.

[18] M. M. Mahmoud, M. M. Aly, H. S. Salama, and A. M. M. Abdel-Rahim, "A combination of an OTC based MPPT and fuzzy logic current control for a wind-driven PMSG under variability of wind speed," Energy Syst., 2021, DOI: 10.1007/s12667-021-004682.

[19] P. P. Pradhan and B. Subudhi, "An ARMAXDFIG model-based adaptive controller for a wind energy conversion system," Wind Eng., 2021, DOI: 10.1177/0309524X211000718.

[20] V. Vanitha and N. Devarajan, "Transient stability improvement of a squirrel cage induction generator in wind farm using STATCOM with supercapacitor," Wind Eng., vol. 36, no. 2, pp. 197-218, 2012, DOI: 10.1260/0309-524X.36.2.197.

[21] B. N. Stram, "Key challenges to expanding renewable energy," Energy Policy, vol. 96, pp. 728-734, 2016, DOI: 10.1016/j.enpol.2016.05.034.

[22] F. Blaabjerg and K. Ma, "Future on power electronics for wind turbine systems," IEEE J. Emerg. Sel. Top. Power Electron., vol. 1, no. 3, pp. 139-152, 2013, DOI: 10.1109/JESTPE.2013.2275978.

[23] T. Report, E. Efficiency, P. Alto, E. A Demeo, and G. Group, "Renewable Energy Technology Characterizations," US Dep. Energy, vol. TR-109496, no. December, pp. 1-283, 1997, [Online]. Available: http://www.mendeley.com/research/renewableenergy-technology-characterizations/.

[24] C. a Walford, "Wind turbine reliability: understanding andminimizing wind turbineoperation andmaintenance costs," Energy, no. March, pp. SAND2006-1100, 2006, [Online]. Available: http://prod.sandia.gov/ techlib/access- control.cgi/2006/061100.pdf. 


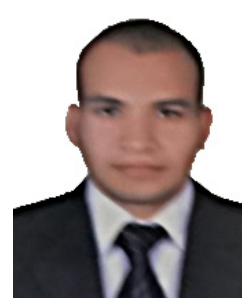

Mohamed Metwally Mahmoud received the B.Sc. and M.Sc. degree in Electrical Engineering from Aswan University, Aswan, Egypt, in 2015 and 2019, respectively. Since, 2017 he has been with the Department of Electrical Engineering, Aswan University, as a Teaching Assistant. His research interests include performance improvement of wind generators, optimization methods, FLC method, fault ride through capability, and energy storage systems.

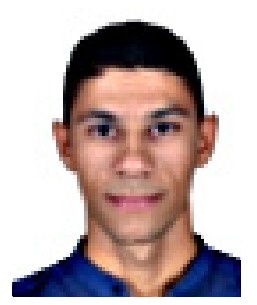

Mohamed Khalid Ratib received the B.Sc. and M.Sc. degree in Electrical Engineering from Aswan University, Aswan, Egypt, in 2016 and 2020, respectively. Since, 2017 he has been with the Department of Electrical Engineering, Aswan University, as a Teaching Assistant. His research interests include power converters, MPC technique, PWM techniques.

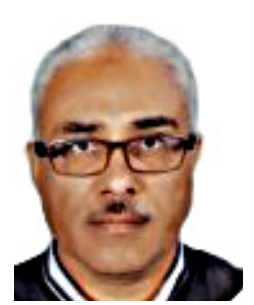

Mohamed M. Aly received the B.Sc. degree in Electrical Engineering from Assuit University, Assuit, Egypt, in 1995. He received both M.Sc. and Ph.D. from UK. Now, he is a full professor at the Department of Electrical Engineering, Aswan University. His research interests include renewable energy systems, power system stability, fault current limiter, and energy storage systems.

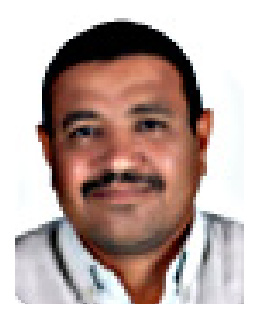

Abdel-Moamen M. Abdel-Rahim received the B.Sc. and M.Sc. degrees in Electrical Engineering from Assuit University, Assuit, Egypt, in 1992, and 1997 respectively. Since, 1994 he has been with the Department of Electrical Engineering, Aswan University, as a Teaching Assistant. His research interests include optimal power flow, and FACTS tools. 